Proc. Indian Acad. Sci. (Earth Planet. Sci.), Vol. 90, No. 3, November 1981, pp. 237-244.

(c) Printed in India.

\title{
A possible explanation of conductivity anomalies near Ujjain and Jaipur
}

\author{
A $K$ AGARWAL \\ Indian Institute of Geomagnetism, Colaba, Bombay 400 005, India \\ MS received 5 March 1981 ; revised 12 June 1981
}

\begin{abstract}
Short-period events such as bays and SSCs have been analysed to investigate the nature of conductivity anomalies at two Indian magnetic observatories: Ujjain (UJJ) and Jaipur (JAI). The induction vectors calculated for these events indicate a high electrical conductivity contrast to the north-west of these stations. To determine an exact cause of anomaly, the direction of induced electric currents is estimated from horizontal disturbance vector $\left(\Delta \vec{B}_{A}\right)$ taking Alibag (ABG) as a normal station. These induced currents are found to flow south-west near JAI and westward near UJJ. It is suggested that possible cause of anomaly at J.AI is a sub-surface conductivity contrast (possibly asthenospheric upwelling) along the Aravalli belt where high heat flow measurements have been reported. At UJJ, an approximately east-west conductor north of it seems to be responsible for conduclivity anomalies.
\end{abstract}

Keywords. Conductivity anomalies; induction vector; horizontal disturbance vector.

\section{Introduction}

Ujjain (UJJ) and Jaipur (JAI) are two permanent magnetic observatories situated in the north-western central plains of India (Lat : $23^{\circ} 11^{\prime} \mathrm{N}$, Long. $75^{\circ} 47^{\prime} \mathrm{E}$ for UJJ and Lat. $26^{\circ} 55^{\circ} \mathrm{N}$, Long. $75^{\circ} 48^{\circ} \mathrm{E}$ for JAI). The latitudinal dependence of geomagnetic variations during storm-time variations at these two stations exhibits the following important characteristics in comparison to other low-latitude Indian stations (Agarwal et al 1979) : (i) the day-time enhancement of variations is moderate without the influence of equatorial electrojet (ii) amplitude of $\mathrm{H}$ variations at UJJ is larger than that of JAI and $A B G$ (iii) the $Z$-variations at UJJ and JAI are negative similar to coastal anomalous station Alibag (ABG). Srivastava (1977) has discussed the anomalously large negative $Z$-amplitudes of rapid geomagnetic variations in west central India including Ujjain and Jaipur, and correlated them with high heat flow values and an upwelling of the upper mantle in the region.

The geomagnetic variations observed at a station consist of two parts : (i) an external part caused by ionospheric and extraionospheric currents and (ii) an 
internal part due to currents induced in earth's interior by (i). The effect of induced current adds up in horizontal components ( $H$ and $D$ ) whereas in vertical component $(Z)$ the two oppose each other. Thus the vertical component is a more reliable signature for identifying sub-surface local conductivity contrasts. In low-latitude stations, normal value of $Z$ is expected to be small and positive as is observed at an inland station Hyderabad (HYB). This has been pointed out first by Silsbee and Vestine (1942) who have also given current distribution for bays. In contrast, distinct negative $Z$-variations at UJJ and JAI indicate that the geology of the region must have some anomalous geological features near these stations. The latitudinal dependence of amplitude of $H$-variations from ABG to JAI further confirms the above possibility as it does not fit into the trend of gradual increase northwards of $H$-amplitude (Schmucker 1969). To identify an exact cause of anomalies, induction vectors (Wiese 1962; Parkinson 1959) and horizontal disturbance vectors (Schmucker 1969) are computed from the analysis of short-period events such as bays and SSCs. These parameters are very useful to both identify and locate internal currents (Nityananda et al 1977) causing the anomaly. The present paper reports such an analysis for UJJ and JAI.

\section{Analysis}

In order to investigate the nature of induced magnetic variations in vertical component $(Z)$, about 40 night-time bays and SSCs have been selected for the present purpose. The variations of a typical night-time bay at low-latitude Indian stations (HYB, ABG, UJJ and JAI) are shown in figure 1. The nighttime events chosen as external fields are then expected to be more uniform over a large extent in low-latitudes (Obayashi and Jacobs 1957; Schmucker 1969). All events are scaled from magnetograms to give amplitudes of $\triangle H, \triangle D$ and $\triangle Z$. It has been assumed that $\triangle Z$ is largely of internal origin and is related to $\triangle H$ and $\triangle D$ through the following equation :

$$
\Delta \mathrm{Z}=A \cdot \Delta H+B \cdot \Delta D+\varepsilon
$$

where $A$ and $B$ are constants and $\varepsilon$ denotes the uncorrelated part of $\Delta Z$ which could account for its internal component.

By subjecting the events to a least-square fit, the coefficients $A$ and $B$ are calculated to give an induction vector $\vec{S}\left[=\left(A^{2}+B^{2}\right)^{1 / 2}\right]$ and its azimuth ( $\theta=$ $\left.\tan ^{-1} B \mid A\right)$. The induction vectors thus found, for bays and SSrs at both stations are shown in figure 2 on the map of India.

To determine whether the anomalies in horizontal components exist or not, the latitudinal trend of mean directions of horizontal variations at UJJ and JAI are compared with the mean direction at the reference station $A B G$. ABG has been chosen as a reference station since its mean direction of horizontal variations is not very much different from that of an inland normal station HYB (Nityananda et al 1977). For computing mean directions of horizontal variations at all three stations, amplitude of selected events are plotted with $\triangle H$ in nanoteslas on $Y$-axis (representing north) and $\triangle D$ also in nanoteslas on 


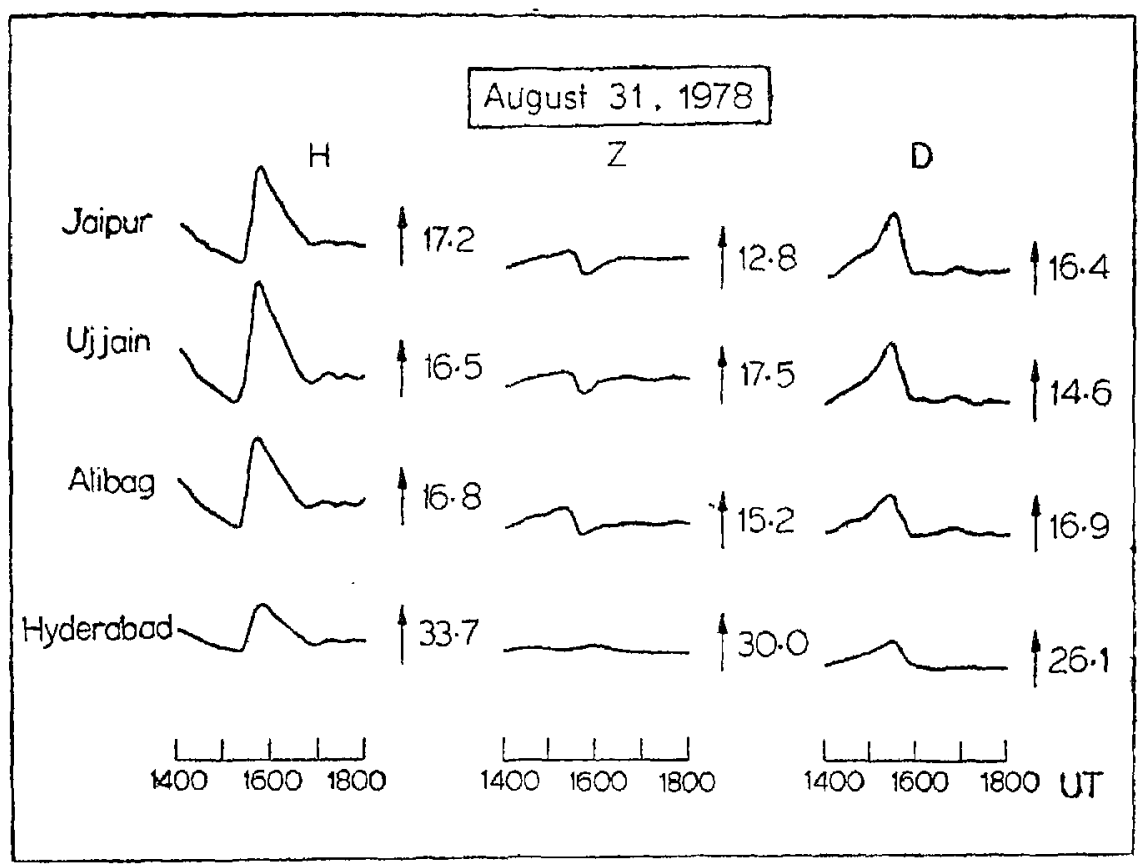

Figure 1. Amplitude variations during a typical magnetic bay observed at low-latitude Indian stations. Units marked are scale values, nT/cm. Time marked on $X$-axis is in UT.

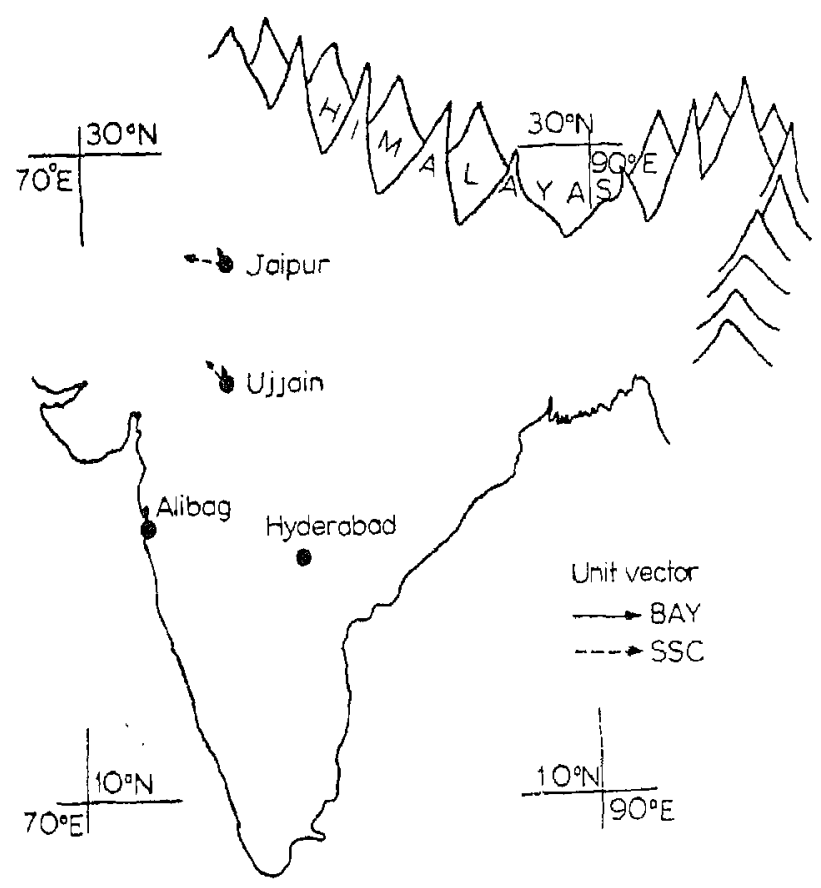

Figure 2. The induction vectors at Ujjain and Jaipur for bays and SSCs events. 
$X$-axis (representing east). Figure 3 shows mean direction of horizontal variations obtained by best-visual fit at all three stations for bays and SSCs. In both cases, the mean directions at UJJ and JAI do not fit in latitudinal trend of gradual shift toward east indicating an anomalous behaviour at these stations. At UJJ, the change in direction is slightly more eastward whereas at JAI it is west of $A B G$. These changes in mean directions cannot be ascribed to latitudinal variations as Schmucker et al (1966) have shown from their studies in Peru and Bolivia that for night-time bays there is a very little change in horizontal components over $37^{\circ}$ of latitude (northward gradient of $5 \%$ per hundred kilometers in $H$ and negligible eastward gradient in $D$ ).

For identifying the nature of anomalies in horizontal components, we have computed horizontal disturbance vectors $\left(\Delta \overrightarrow{B_{\mathrm{A}}}\right)$ as defined by Schmucker (1969). For this, anomalous part in the horizontal components $\left(\triangle H_{\mathrm{A}}\right.$ and $\left.\triangle D_{\mathrm{A}}\right)$ at UJJ and JAI are calculated from algebraic difference between their horizontal components at these stations and the normal station at $A B G$ for all possible common events. The anomalous parts $\Delta H_{\mathrm{A}}$ and $\Delta D_{\mathrm{A}}$ are plotted

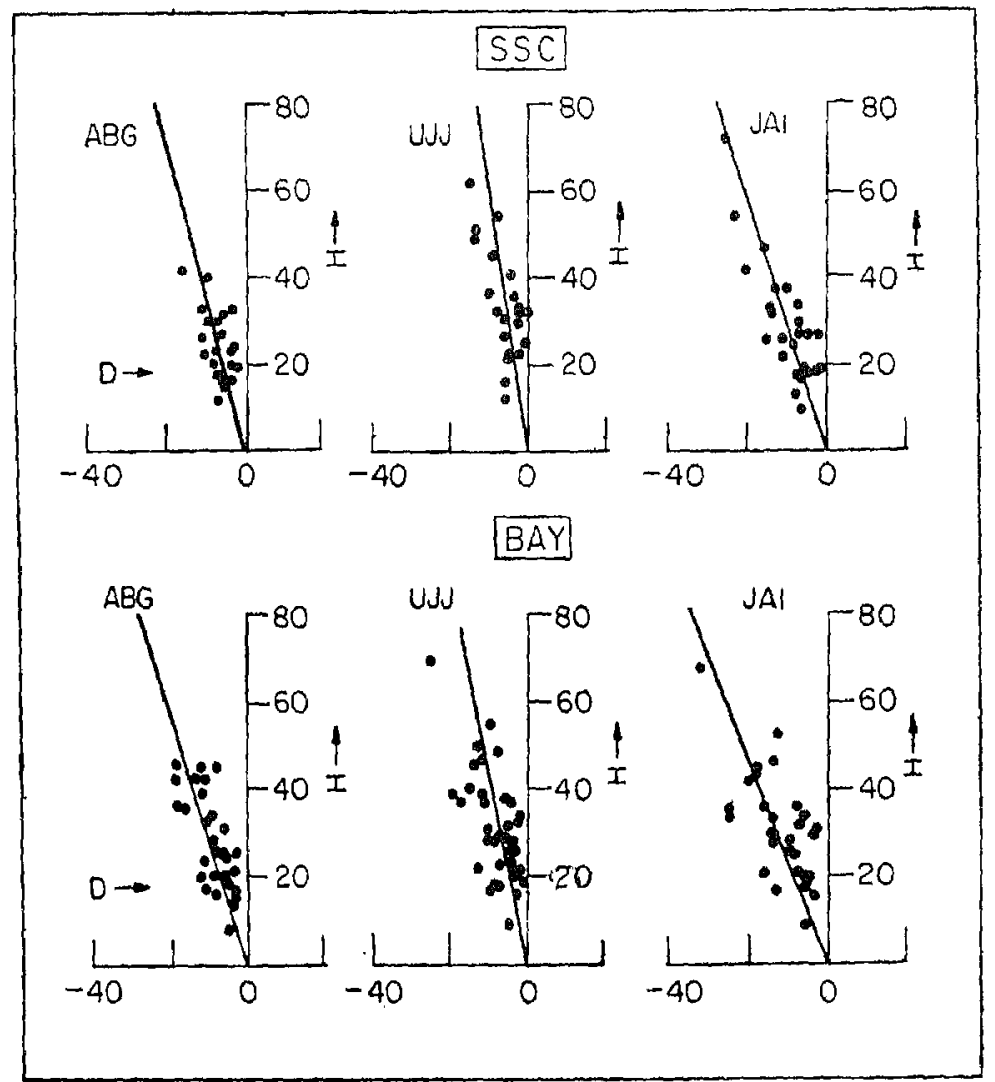

Figure 3. Mean direction of horizontal variations at Alibag, Ujjain and Jaipur for bays and SSCs events. 
again taking $\Delta H_{\mathrm{A}}$ on $Y$-axis and $\Delta D_{\mathrm{A}}$ on $X$-axis. Figure 4 shows such plots at the two stations for bays and SSCs. The mean direction of vectors is obtained by least-square fit. These vectors point towards $139^{\circ} 5$ (measured clockwise from south) for SSCs and $131^{\circ} .0$ for bays at JAI and $193^{\circ} .0$ and $184^{\circ} .5$ for SSCs and bays respectively at UJJ. The direction of induced currents is obtained by rotating this vector anticlockwise through $90^{\circ}$ (Schmucker 1969).

\section{Results and discussion}

It is seen from figure 2 that induction vectors at UJJ point towards $10^{\circ} .7 \mathrm{~W}$ of north for bays and $42^{3} .5 \mathrm{~W}$ of north for SSCs whereas at JAI it is $20^{\circ} .2 \mathrm{~W}$ of north for bays and $74^{\circ} .3 \mathrm{~W}$ of north for SSCs. The magnitude $(\vec{S})$ and directions $(\theta)$ of induction vectors are also given in table 1 . This indicates that the conductor causing the anomaly lies approximately north-west of these stations. Similar results have been reported earlier by Srivastava and Abbas (1980).

The directions of induced electric currents inferred from anomalous horizontal vatiations are found to be $49^{\circ} .5$ (measured clockwise from south) for SSCs and $41^{\circ} .0$ for bays at JAI whereas at UJJ it is about $103^{\circ} .0$ and $94^{\circ} .5$ for SSCs and bays respectively. It implies that currents would flow approx NE-SW near JAI possibly along the Aravalli belt where high heat flow measurements have been

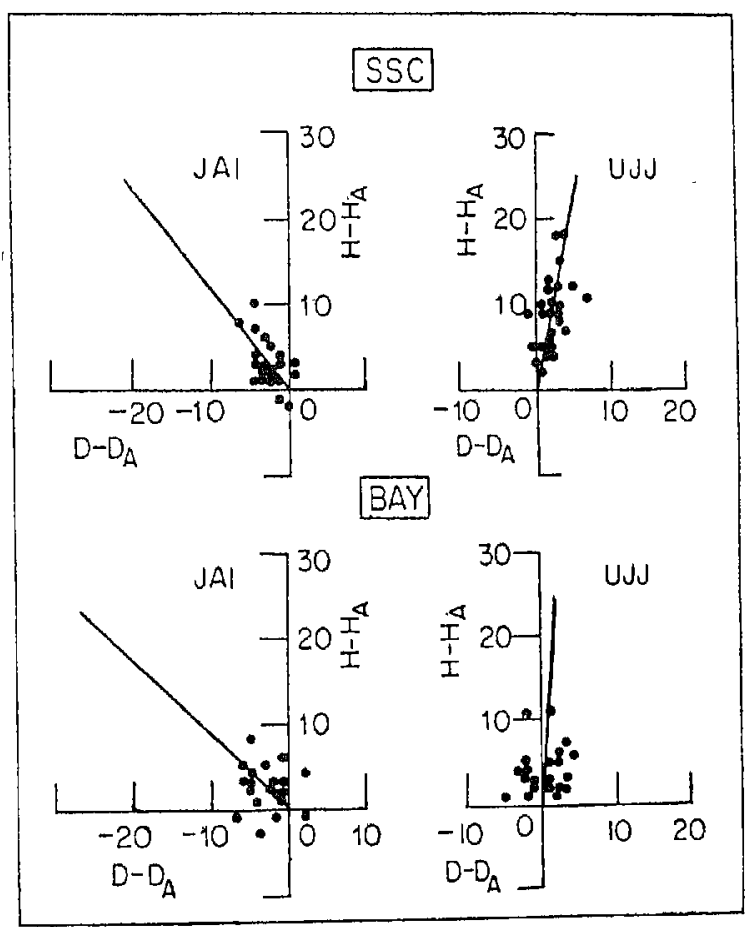

Figure 4. Mean direction of anomalous horizontal variations at Ujjain and Jaipur are obtained after subtraction of the amplitudes observed at Alibag ( $D_{\mathrm{A}}$ and $H_{\mathrm{A}}$ ) which is taken to be a normal station. Units marked on the axes are nT. 
Table 1 . The magnitude $\overrightarrow{(S)}$ and direction $(\theta)$ of induction vectors obtained at UJJ and JAI for both bays and SSCs.

\begin{tabular}{|c|c|c|c|c|c|}
\hline \multirow{3}{*}{ Station } & \multirow{3}{*}{ Code } & \multicolumn{4}{|c|}{ Induction vector } \\
\hline & & \multicolumn{2}{|c|}{ Bays } & \multicolumn{2}{|c|}{ SSCS } \\
\hline & & $\vec{S}$ & $\theta^{*}$ & $\vec{S}$ & $\theta^{*}$ \\
\hline Ujjain & $\mathrm{UJJ}$ & 0.17 & $169.3^{\circ}$ & 0.26 & $137.5^{\circ}$ \\
\hline Jaipur & JAI & 0.13 & $159.8^{\circ}$ & 0.37 & $105.7^{\circ}$ \\
\hline
\end{tabular}

*measured clockwise from South.

reported by Verma et al (1968). It may be noted that Aravalli belt has been pictured by Heron (1953) as NE-SW trending anticlinorium constituted of Aravalli and Delhi groups of rocks, the latter occupying the core. Further high heat flow measurements indicate that some geological structure in the sub-basement is of abnormally high electrical conductivity contrasts. Therefore it may be suggested that increased electrical conductivity contrast is possible from an upwelling of highly conducting asthenosphere along the Aravalli belt. However at UJJ, direction of induced currents is found to flow approx. east to west and it is north of the station. The most conspicuous and well-defined tectonic feature in this area is Narmada-Son lineament which is clearly evident in seismic (Naqvi et al 1974) and gravity profiles (Qureshy et al 1968). Although this zone is known to be buried by a thick layer of sediments (Mishra 1977), yet it does not seem to be a possible source of anomaly at UJJ. Because this feature lies south of UJJ, a westward direction of induced current flow in this structure will give positive $Z$-anomaly. On the contrary, observed anomaly in $Z$ at UJJ is negative which requires approx. east-west conductor in the north side. Lilley et al (1980) analysed the magnetic array data in north-west India and indicated a major conductivity contrast along the Aravalli beit. A close examination of $Z$-cosine and $Z$-sine maps in their paper (figure 4) suggests that a conductivity contrast also exists in approx. E-W direction which is shown by zero-level contour pattern in their curve. These results further confirm our supposition for conductivity contrast near UJJ on northern side which needs detailed investigation.

To investigate the nature and depth of conductor, we have utilised horizontal $\rightarrow$

disturbance vector $\left(\triangle B_{\mathrm{A}}\right)$. We have computed the ratio

$$
\left|\frac{\triangle B_{\mathrm{A}}}{\triangle Z_{\mathrm{A}}}\right|
$$

for each event and then averaged them over all events in each class where

$$
\Delta \overrightarrow{B_{\mathrm{A}}}=\left(\Delta H_{\mathrm{A}}^{2}+\Delta D_{\mathrm{A}}^{2}\right)^{1 / 2}
$$

The anomalous variation $\left(\triangle Z_{A}\right)$ is taken to be the total amplitude of 
observed variation in vertical component. Lilley (1976) has suggested that a response arrow scaled as arctan

$$
\left(\left|\frac{\triangle B_{\mathrm{A}}}{\triangle Z_{\mathrm{A}}}\right|\right)
$$

be plotted in the direction of $\triangle B_{\mathrm{A}}$ if $\triangle \mathrm{Z}_{\mathrm{A}}$ is negative, and in the direction of $\rightarrow$

$-\triangle B_{\mathrm{A}}$ if $\triangle Z_{\hat{\Lambda}}$ is positive thereby obtaining antarrow whose length is maximal and finite directly over the current. The magnitudes of these response arrows together with standard ceviations are found to be $-0.60 \pm 0.24$ for SSCs and -0.85 \pm 0.32 for bays at JAI whereas at UJJ these are $-0.95 \pm 0.24$ and $-0.66 \pm 0.28$ for SSCs and bays respectively. The larger value of response arrow for bays at JAI is indicative of the fact that conductivity contrast exists at a much deeper level possibly in the asthenosphere along the Aravalli belt. For periodicities around SSCs, the induced currents do not penetrate much deeper thereby reducing their contribution which is evident from a smaller value of response arrow. However, at UJJ a larger value of response arrow for SSCs suggests that induced currents are closer to it and they flow at shallow depth. At longer periods, the currents not only flow at shallower depth but also in the upper mantle thereby smearing the overall induced effects at such periods. This is indicated by a smaller value of response arrow for bays. Thus a deep-seated conductor together with surface conductivity contrast in east-west direction seems to be responsible for anomalies at UJJ. The large value of scatter in magnitude of response arrows at both stations is attributed to the assumption that total $\triangle \mathrm{Z}$ observed at each station is not wholly anomalous.

\section{Conclusions}

The existence of negative Z-variations at UJJ and JAI in comparison to an expected normal positive Z-variations in the north-western plains of India suggests that anomalous effects are present in this area. The directions of induced currents inferred from the nature of horizontal anomalies $\left(\Delta \vec{B}_{\mathrm{A}}\right)$ indicate that a deep-seated conductivity contrast possibly an upwelling of an asthenosphere along the Aravalli belt is a cause of conductivity anomalies at JAI. At UJJ, an approximate east-west conductor north of it is responsible for anomalies. It is surprising to note that the signature of a major geological feature i.e. Narmada-Son lineament which is known to be tectonically active does not seem to be significant in magnetic records at UJJ. Further confirmation of the results and a clear picture of sub-surface conductivity structure in this area will emerge only when some more results from magnetic array data will be available.

\section{Acknowledgements}

The author is grateful to Dr B P Singh and Mrs N Nityananda for many useful discussions and their encouragement during the progress of this work. 


\section{References}

Agarwal A K, Singh B P and Nityananda N 1979 Phys. Earth Planet. Inter. 18232

Heron A M 1953 Mem. Geol. Surv. India 99389

Lilley F E M 1976 Geophys. J. R. Astron. Soc. 46165

Lilly F E M, Singh B P, Arora B R, Srivastava B J, Prasad S N and Sloane M N 1980 Phys. Earth Planet. Inter. [in press]

Mishra D C 1977 Earth Planet. Sci. Lett. 36301

Naqvi S M, Rao V D and Narain H 1974 Precambrian Res. 1345

Nityananda N, Agarwal A K and Singh B P 1977 Phys. Earth Planet. Inter. 155

Obayashi T and Jacobs J A 1957 J. Geophys. Res. 62589

Parkinson W D 1959 Geophys. J. R. Astron. Soc. 21

Qureshy M N, Brahmam N K, Garde S C and Mathur S K 1968 Bull. Geol. Soc. Am. 791221

Schnucker $U 1969$ in Applications of modern physics to the earth and planetary interiors. [ed.] S K Runcorn [New York: Interscience] 125

Schmucker U, Forbush S E, Hartmann O, Giesecke A A, Casaverde M, Castillo J, Salgueiro R and Pozo S del 1966 Carnegie Inst. Wash. Yearbook 6511

Silsbee H C and Vestine E H. 1942 Terr. Mag. Atmos. Electr. 47195

Srivastava B J 1977 Proc. of workshop on equatorial electrojet and associated phenomena, Physical Research Laboratory, Ahmedabad p. 27

Srivastava B J and Abbas H 1980 J. Gcomag. Geoelectr. 32 Suppl. I, SI, 187

Verma R K, Rao R U M, Gupta M L, Hamza V M and Rao G V 1968 Bull. Volcanol. 3369

Wiese H 1962 Geofis. Pure Appl. 5159 